IMECE2015-50930

\title{
THERMO-STRUCTURAL DESIGN OF THE HEXAFLY-INT EXPERIMENTAL FLIGHT TEST VEHICLE (EFTV)
}

\author{
Roberto Scigliano \\ Italian Aerospace Research Centre (CIRA) \\ Capua, Italy
}

\author{
Valerio Carandente
space Research Centre (CIRA) \\ Valerio Carandente
Italian Aerospace Research Centre (CIRA) \\ Capua, Italy
}

\author{
Salvatore Cardone
cnosistem Engineering \& \\ Salvatore Cardone
Tecnosistem Engineering \& \\ Technology \\ Naples, Italy
}

\author{
Johan Steelant \\ European Space Agency (ESA) \\ Noordwijk, Netherlands
}

\author{
Nunzia Favaloro \\ Italian Aerospace Research \\ Centre (CIRA) \\ Capua, Italy
}

\begin{abstract}
The Hexafly-INT project intends to test in free-flight conditions an innovative gliding vehicle with several breakthrough technologies on-board. This approach will create the basis to gradually increase the readiness level of a consistent number of technologies suitable for high-speed flying systems.

This paper presents a Finite Element thermal analysis of the Experimental Flight Test Vehicle, combining information coming from the flight trajectory, the structural layout, the vehicle aerothermodynamics and the thermal behavior of the preliminarily selected materials in high temperature conditions. Numerical results show the thermal performances of the selected high temperature resistant materials in moderate enthalpy flow conditions and provide fundamental information on the thermal loads to be considered for structural analyses.
\end{abstract}

\section{INTRODUCTION}

Over the last years, innovative concepts of civil high-speed transportation vehicles and the development of related technologies were proposed in European Commission cofunded projects like ATLLAS, LAPCAT and HEXAFLY $[1,2,3]$. These vehicles have a strong potential to increase the cruise range efficiency at high Mach numbers, thanks to efficient propulsion units combined with high-lifting vehicle concepts $[4,5]$.

Nonetheless, performing a flight test will be the only and ultimate proof to demonstrate the technical feasibility of these new promising concepts and technologies and would result into a major breakthrough in high-speed flight. At present, the expected performances are usually demonstrated by numerical simulations and only partly by experimental tests. As high-speed wind tunnels are intrinsically limited in size, it is nearly impossible to completely fit even modest vehicle planform into a tunnel. Though numerical simulations are less restrictive in geometrical size, they struggle however with accumulated uncertainties in their modelling, making predictions doubtful without inflight validation. As a consequence, the obtained technology developments are now limited to a Technology Readiness Level (TRL) equal to 4 (components validated in laboratory).

The HEXAFLY-INT project aims at the free flight testing of an innovative high-speed vehicle with several breakthrough technologies on board [6,7]. This approach will create the basis to gradually increase the TRL.

The vehicle design, manufacturing, assembly and verification will be the main driver and challenge in this project, in combination with a mission tuned sounding rocket. The prime objectives of this free-flying high-speed cruise vehicle shall aim at [4]:

- a conceptual design demonstrating a high aerodynamic efficiency at cruise conditions with a high volumetric efficiency;

- a positive aerodynamic balance at a controlled cruise Mach numbers from 7 to 8 ;

- a good gliding performance from Mach 7 to 2;

- an optimal use of advanced high-temperature resistant materials and/or structures. 
The main flight sequence profile and mission events are shown in Figure 1 and listed in Table 1 [5,8,9]. In particular, from Figure 1 and Table 1 it is evident that the separation between the launcher and the whole vehicle, consisting of the Experimental Flight Test Vehicle (EFTV) and the Experimental Support Module (ESM), occurs around the apogee of the sounding rocket parabolic trajectory. Then, in the first part of the descent, the vehicle attitude is controlled by the Cold Gas System (CGS) included in the ESM. When the dynamic pressure along the flight path is large enough to guarantee the aerodynamic manoeuvrability of the EFTV, the ESM is released. Finally, after a pull out manoeuvre, the EFTV starts its aerodynamically controlled cruise flight. The analysed EFTV and ESM configurations are shown in Figure 2 [8].

In the present work the methodology and the implementation of tools for thermal analysis of the EFTV, during a preliminarily considered test window, is presented [9]. Thermal analyses are performed on the basis of the trajectory provided by Gas Dynamics Limited (GDL) and of the structural layout developed by Tecnosistem Engineering \& Technology (TET).
In particular, the calculations show a first feasibility analysis for the preliminarily selected materials.

\section{FLIGHT TRAJECTORY}

Flight mechanic analyses developed so far refer to different altitudes of the ESM release from the EFTV. For instance, Figure 3 shows the trajectory obtained for an EFTV mass of $350 \mathrm{~kg}$ assuming the ESM ejection at $50 \mathrm{~km}$ altitude. In particular, Figure 3 provides the time histories of altitude and velocity during descent, starting from the ESM release. This preliminary trajectory results in the most conservative scenario in terms of aero-thermal and mechanical loads available so far. The stagnation point convective heat transfer coefficient profile of the EFTV, provided in non-dimensional form as input to the thermal analysis hereinafter discussed, is shown in Figure 4. It was derived from the corresponding convective heat flux, estimated by means of the Tauber's [10] relationship throughout the descent flight shown in Figure 3. The EFTV nose leading edge radius is $2 \mathrm{~mm}$ and the aerothermal loading conditions refer to radiatively cooled walls with a surface emissivity of 0.4 .

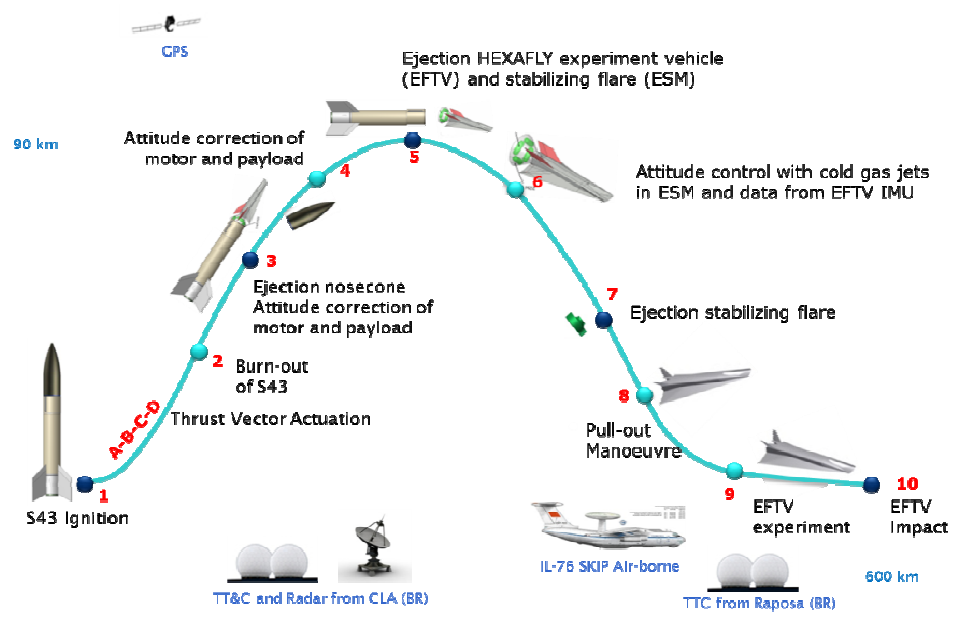

Table 1. Flight sequence events [5]

\begin{tabular}{cc}
\hline$\#$ & Flight Event \\
\hline $\mathbf{1 - 2}$ & Propelled ascent \\
\hline $\mathbf{2}$ & Motor burnout \\
\hline $\mathbf{3}$ & Nose-cone ejection \\
\hline $\mathbf{4}$ & L/V alignment \\
\hline $\mathbf{5}$ & ESM/EFTV release \\
\hline $\mathbf{6}$ & Attitude control by CGS in the ESM \\
\hline $\mathbf{7}$ & Ejection of ESM \\
\hline $\mathbf{8}$ & Pull-out manoeuvre \\
\hline $\mathbf{9}$ & Controlled flight \\
\hline $\mathbf{1 0}$ & Impact \\
\hline
\end{tabular}

Figure 1. Flight sequence profile [5]

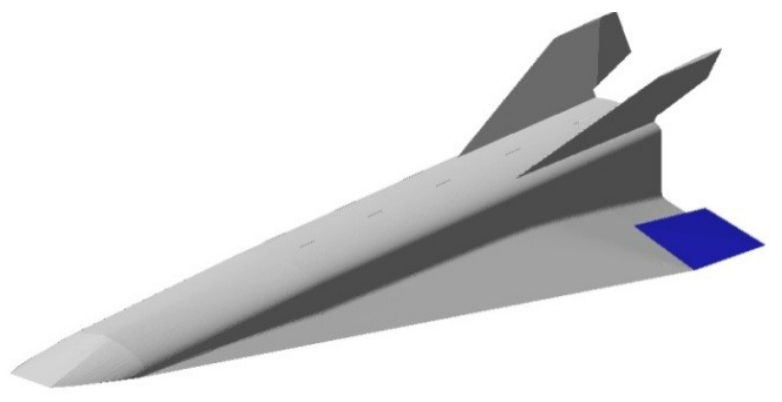

(a)

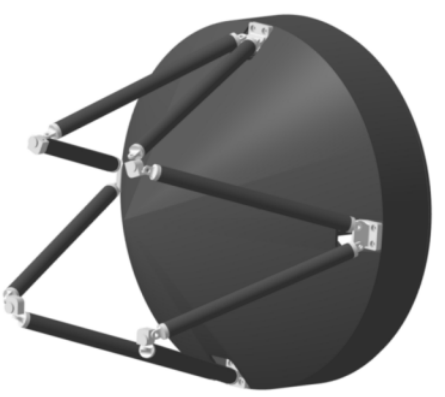

(b)

Figure 2. EFTV (a) and ESM (b) configurations analyzed [8] 


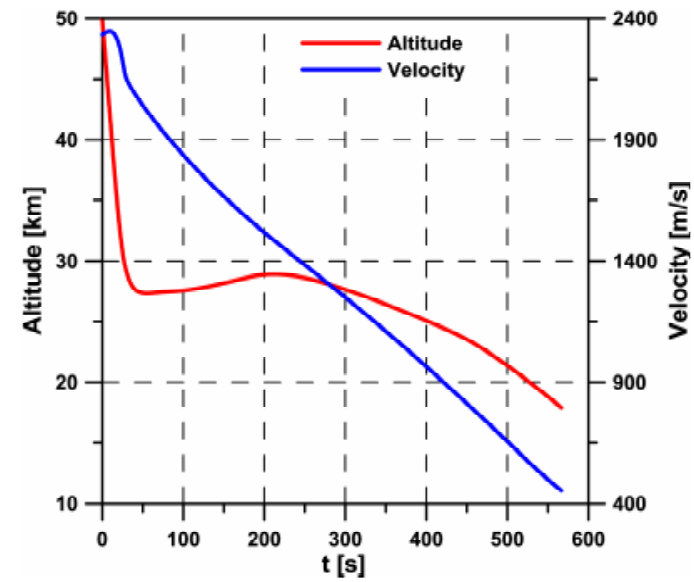

Figure 3. Altitude and velocity profiles for the considered flight path of EFTV vehicle

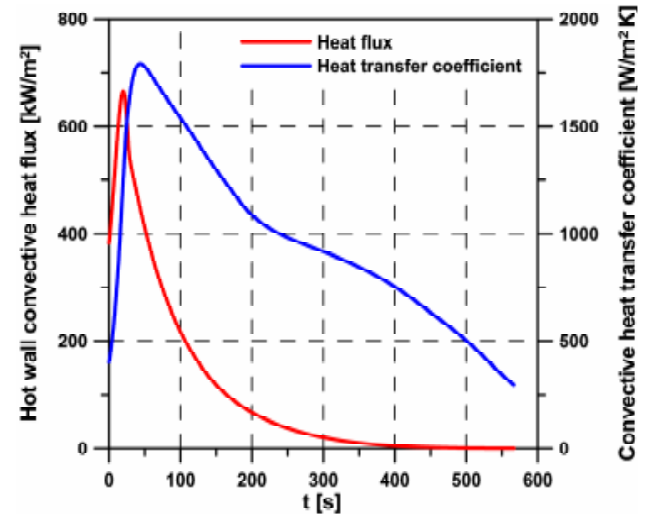

Figure 4. Stagnation point convective heat flux estimated by means of Tauber's formula (radiation equilibrium condition) and corresponding convective heat transfer coefficient along the considered flight path

\section{EFTV CANDIDATE MATERIALS}

Different classes of materials have been preliminarily selected and analyzed for the EFTV structure, namely: titanium alloy, copper, C/C-SiC and zirconia for surface coatings. This should give a first estimate of the characteristic behavior of potential materials specifically for this flight trajectory.

Titanium alloys exhibit a unique combination of mechanical and physical properties and corrosion resistance which have made them desirable for critical, demanding aerospace applications, also in high temperatures conditions. Copper is employed as a heat sink to accommodate the thermal energy in some critical components (e.g. nose, leading edges). C/C-SiC developed at DLR [11] and tested in different high temperatures applications (e.g. HIFiRE and SHEFEX) is considered for ailerons and for the final part of the wing leading edge. A zirconia coating layer has been also considered to protect titanium and copper components, increasing their surface emissivity and confining the larger temperatures on the layer itself.

Thermal and mechanical properties of titanium alloy and zirconia coating have been provided by TsAGI, Tsentralniy Aerogidrodinamicheskiy Institut (Central Aerohydrodynamic Institute), which is in charge of the system manufacturing.

In particular, the following assumptions, reported in Table 2, have been carried out on the vehicle components shown in Figure 7 to assess the correct implementation of the methodology:

- copper for the vehicle nose;

- copper for the fore part of the wing leading edges;

- $\mathrm{C} / \mathrm{C}-\mathrm{SiC}$ for the remaining part of the wing leading edge;

- copper for the leading edge of the V-tails;

- $\mathrm{C} / \mathrm{C}-\mathrm{SiC}$ for the ailerons;

- titanium alloy for the remaining part of the structure.
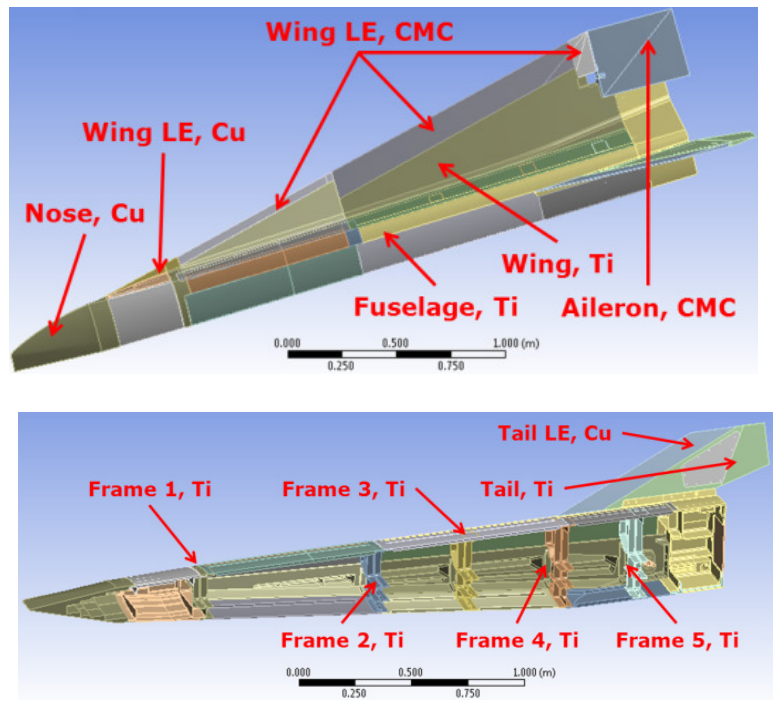

Figure 5. Main structural components of the analyzed EFTV

In addition, as previously mentioned, a layer of $1 \mathrm{~mm}$ thick zirconia has been foreseen for all the components in titanium alloy and copper. Using a conservative approach, a constant surface emissivity of 0.4 has been set for the external coated surfaces.

Table 2.Preliminarily material assignment for the main structural components

\begin{tabular}{ccc}
\hline Nose & Fuselage & Wing \\
\hline Copper & Ti-Alloy & Ti-Alloy \\
\hline Wing LE & V-Tail & Aileron \\
\hline C/C-SiC / & Ti-Alloy / & C/C-SiC \\
Copper & Copper & \\
\hline
\end{tabular}




\section{STRUCTURAL LAYOUT}

The vehicle layout incorporates the contributions provided by the project partners for the following subsystems:

- Cold structure

- Hot structures

- Power System

- Inertial Platform and Flight Control System

- Telemetry and Tele-Command System

- In-Flight Measurement instrumentation

In this paper the cold and the hot structures layout are presented in more details.

\subsection{COLD STRUCTURE}

The cold structures of EFTV are composed mainly by the following major items:
- fuselage

- wings

- rudders

In particular, the fuselage structure will be realized with a buildup approach. Its structure is composed by three main sections:

- forward (FWD) fuselage

- central (CTR) fuselage

- tail fuselage

In Figure 6 the exploded view of the entire vehicle is reported. Figure 7 and Figure 8 show the main fuselage sections. In these figures is possible to identify all the components of the major items.

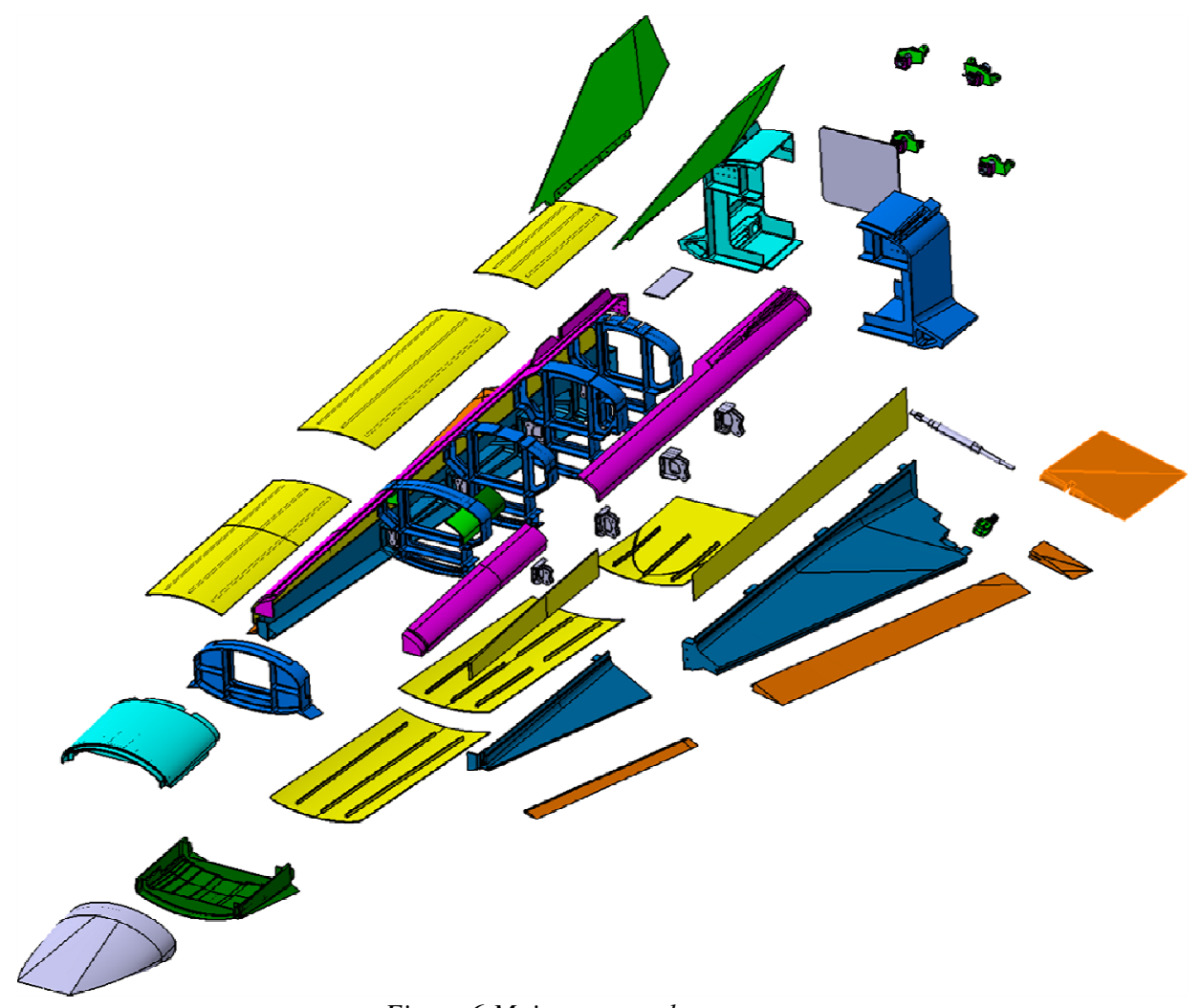

Figure 6.Main structural components 


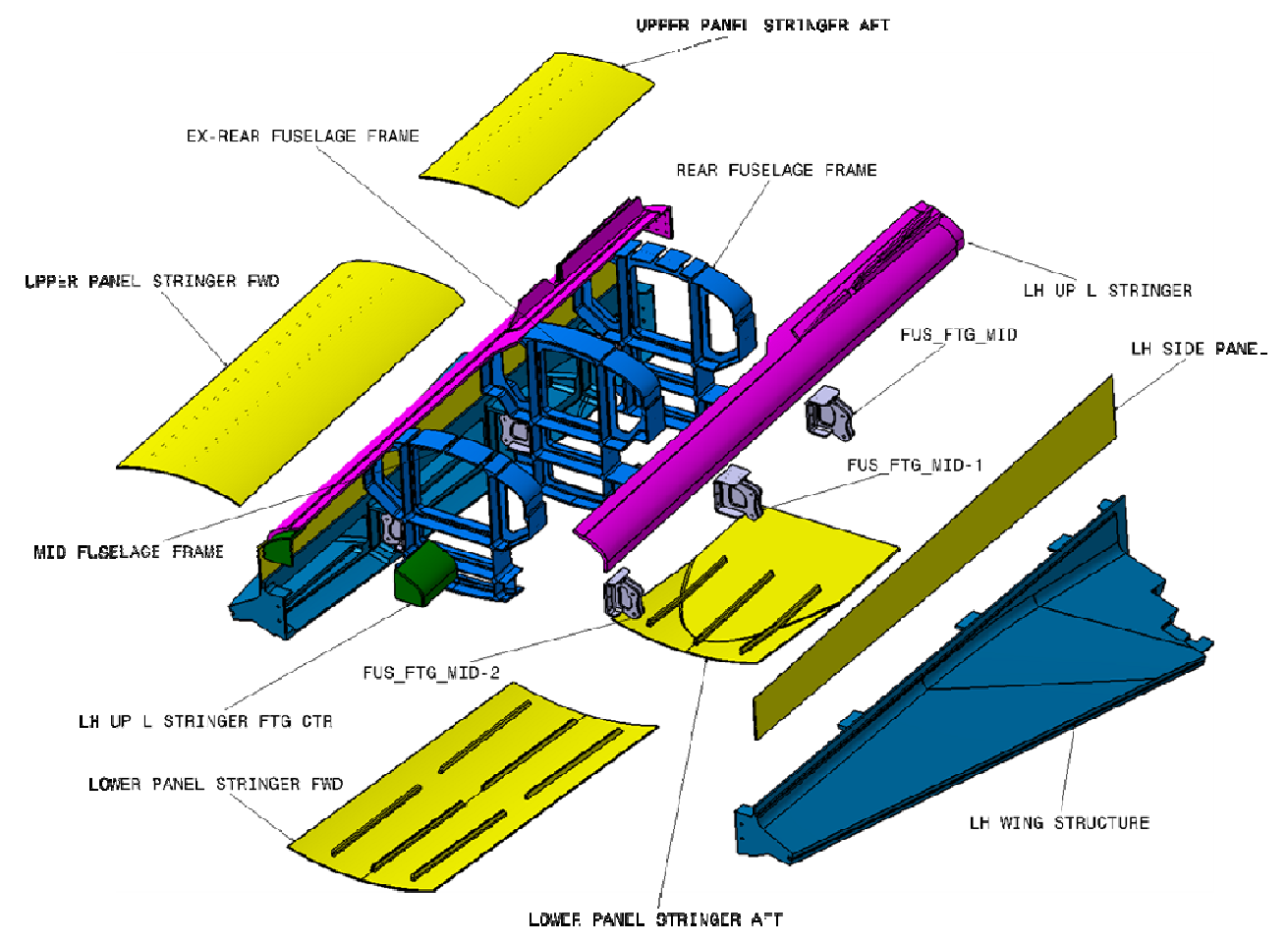

CTR FUSELAGE

Figure 7. CTR fuselage main structural components
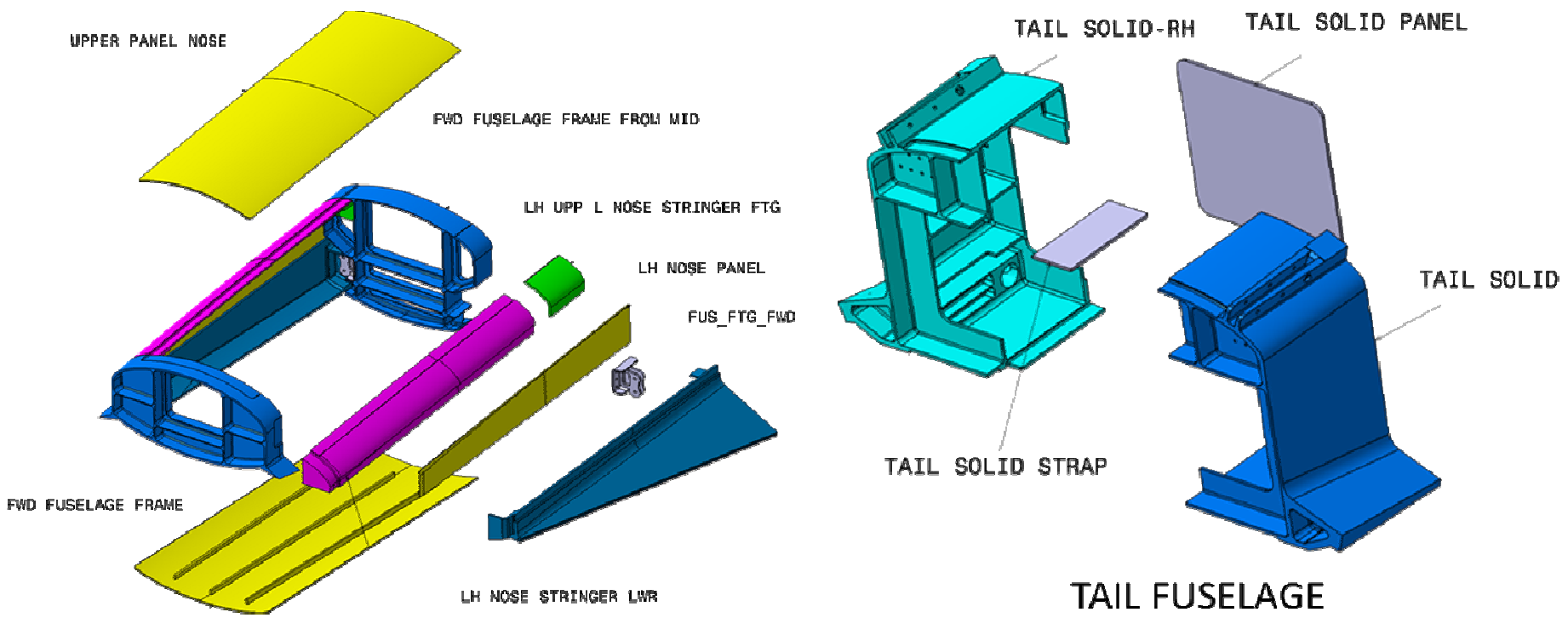

TAIL FUSELAGE

LoWer PANel nOSE

LH UPP L NOSE STRINGER

FWD FUSELAGE

Figure 8. FWD and Tail fuselage main structural components 


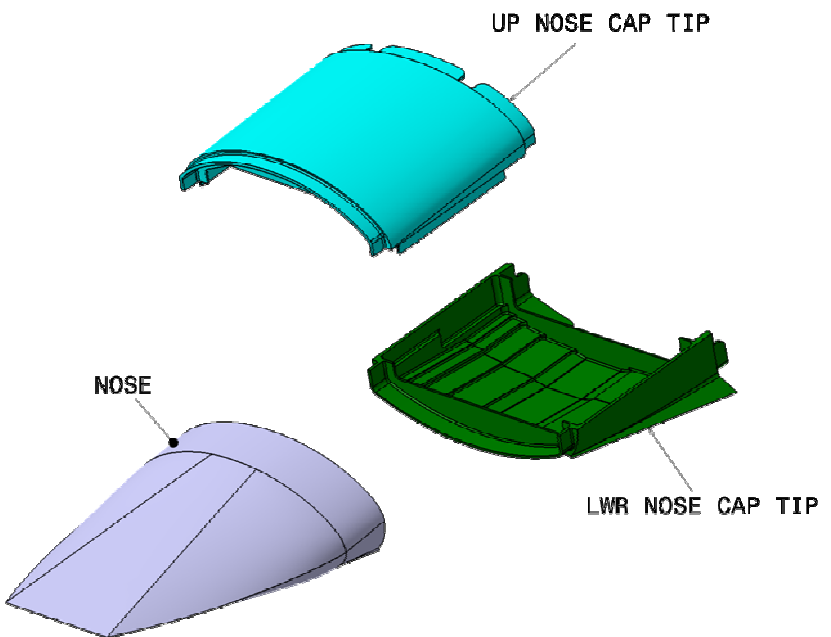

Figure 9. Nosecap structural components

\subsection{HOT STRUCTURE}

The hot structures of EFTV are composed mainly by the following subsystems:

- ailerons

- wing Leading edge

- nose cap

The nose is composed by three parts, one fully solid body in copper and two shells (upper and lower shell), designed in titanium alloy and longitudinally joint one to each other.

For a first approach, the first part of the nose is designed as one fully solid body which can be manufactured as integral part. Considering the large heat fluxes expected on the vehicle nose, copper is chosen for its ability to work as a heat sink. The two shells are manufactured by milling tools, starting from a titanium plate. The junctions will be done by bolts. In Figure 9 the exploded view of nose cap is shown.

Figure 10 reports the aileron and the wing leading edges colored in orange. These components will be made of the C/C$\mathrm{SiC}$ developed at DLR [11].

\section{THERMAL ANALYSIS}

\subsection{NUMERICAL PROCEDURE}

The vehicle thermal behavior has been preliminary assessed by means of the Finite Element Method (FEM) implemented in the software Ansys [12-13]. A transient analysis along the computed entry path is performed to evaluate the time dependent temperature of the structure. In synthesis, as also schematically reported in Figure 11, the following procedure has been carried out:

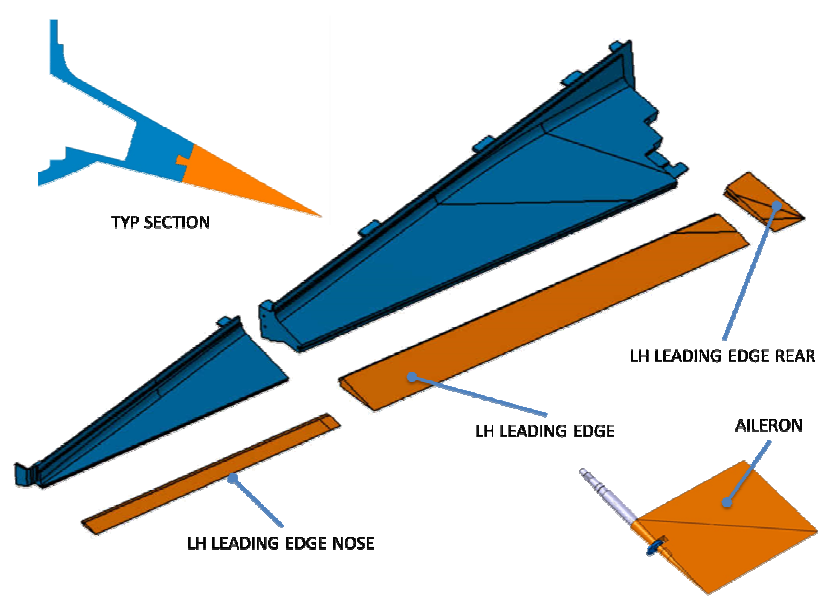

Figure 10. Leading edge and aileron structural components

- the available CAD drawing of the vehicle is implemented in Ansys Workbench and properly modified, if required;

- the computational mesh for the subsequent analyses is generated;

- the transient thermal analysis is set assuming as boundary condition the convective heat transfer coefficient spatial distribution over the vehicle surface, evaluated in a certain number of flight conditions by means of stationary CFD calculations. These distributions are properly scaled by the stagnation-point heat transfer coefficient variation along the trajectory, normalized with respect to the corresponding reference condition (see Figure 11). A radiative dissipation condition is also considered for all the external surfaces;

- static structural computations can be then carried out, if required, in the most critical conditions along the trajectory, assigning as boundary conditions the temperature distributions previously evaluated at selected instants along the trajectory and the pressure distribution resulting from CFD analyses.

As previously mentioned, the boundary condition for the transient thermal analysis has been assigned in terms of the convective heat transfer coefficient, so that the FE numerical code can take into account the effective heat flux entering the structure as the wall temperature increases under the heating process. The stagnation-point convective heat transfer coefficient variation over the trajectory has been obtained from the corresponding convective heat flux profile, estimated by means of the Tauber's [10] relationship throughout the descent flight (see Equation 1, valid assuming an ideal gas condition and a constant specific heat). 


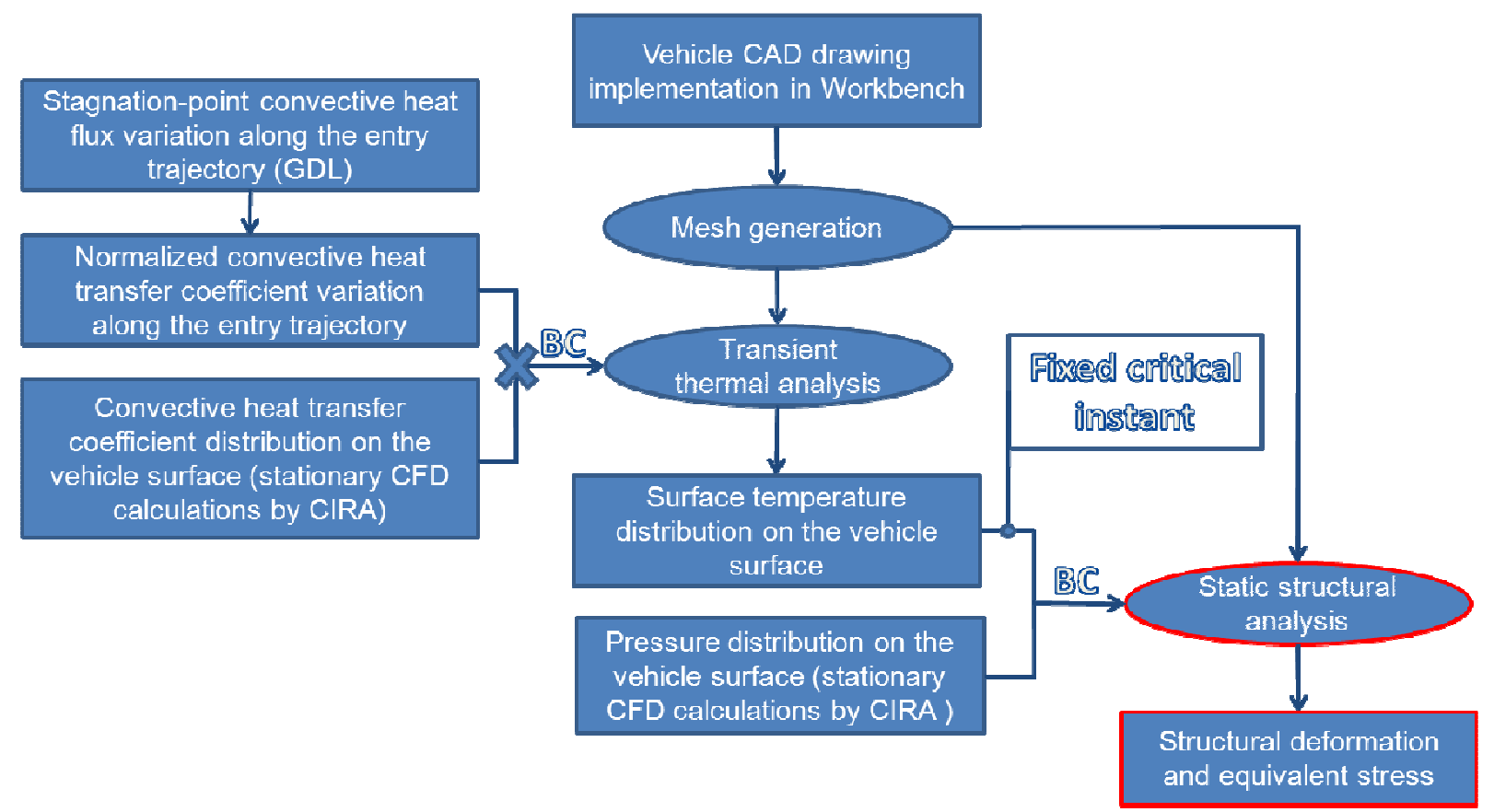

Figure 11. Numerical procedure flow chart

$$
\begin{aligned}
& \dot{q}=h \cdot\left(T_{0}-T_{w}\right) \approx \frac{\dot{q}_{c w}}{T_{a w}} \cdot\left(T_{a w}-T_{w}\right)= \\
& =\frac{\dot{q}_{h w, e q}}{T_{a w}-T_{w, e q}} \cdot\left(T_{a w}-T_{w}\right)
\end{aligned}
$$

It is clear that the convective heat transfer coefficient at any point of the vehicle surface and at a certain time instant can be obtained multiplying the value of the heat transfer coefficient at the selected spatial point (resulting from the CFD calculation), by the normalized stagnation-point convective heat transfer coefficient along the flight path at the selected time instant.

\subsection{PRELIMINARY RESULTS}

As results, according to the previously discussed method, the temporal variation of the maximum temperature on the different analysed materials and vehicle components has been plotted along the flight path. Figure 12 reports in particular the maximum temperature variation along the flight profile on the main vehicle components.

From Figure 12 it can be seen that zirconia coatings and C/C$\mathrm{SiC}$ components (having maximum service temperatures in the order of $2400^{\circ} \mathrm{C}$ and $1600^{\circ} \mathrm{C}$, respectively) would widely survive the aerothermal environment in these conditions. On the other hand, it can be noted that the maximum temperatures on the titanium and copper structures slightly exceed their upper working temperature limits $\left(600\right.$ and $800^{\circ} \mathrm{C}$, respectively), but only in limited spots of the vehicle, coloured in red for the titanium structure in Figure 13. This means that such temperature overshoot can be in principle redistributed inside the vehicle structure through a future thermal structural optimization.

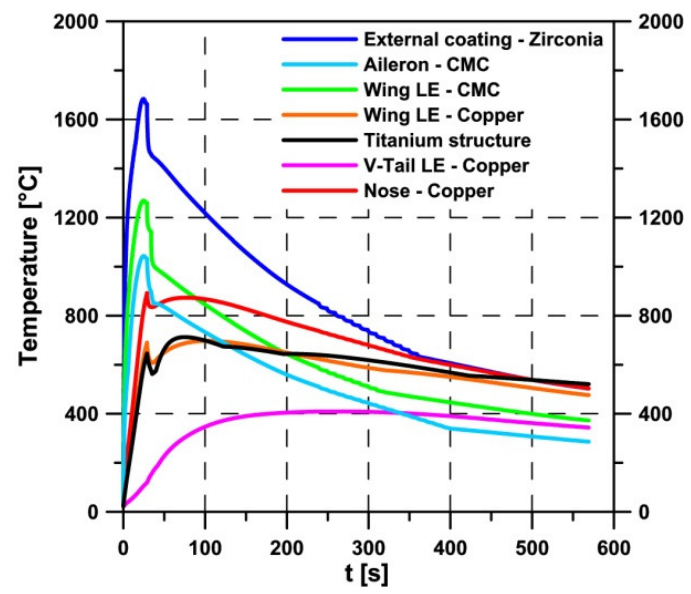

Figure 12. Maximum temperature along the flight profile on the main vehicle components 

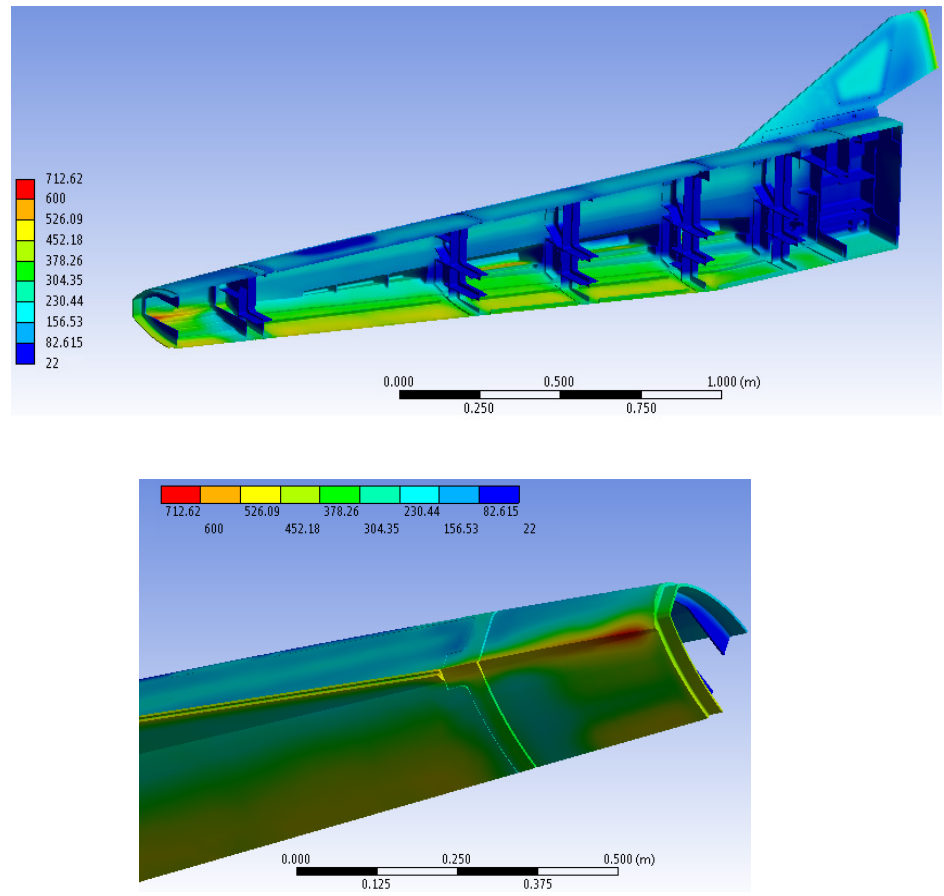

Figure 13. Temperature distribution, at the peak heating condition for titanium components

\section{CONCLUSIONS}

Finally, it can be concluded that:

- a thermal model has been realized for the entire structure on the basis of aero-thermal loads estimated along the flight path;

- zirconia coating guarantees a relatively large surface emissivity and a suitable thermal protection for the underlying materials;

- copper seems to be adequate for the nose and the first part of the wing leading edge, considering its ability to work as a heat sink;

- copper and titanium structures can withstand the aerothermal environment except for limited spots, requiring a proper thermal structural optimization;

- thermal structural design is still ongoing and a numerical analysis campaign will be perform on updated structural configuration, flight trajectory and aerothermal environment.

\section{ACKNOWLEDGMENTS}

This work was performed within the 'High-Speed Experimental Fly Vehicles-International' project fostering International Cooperation on Civil High-Speed Air Transport Research. HEXAFLY-INT, coordinated by ESAESTEC, is supported by the EU within the 7th Framework Programme Theme 7 Transport, Contract no.: ACP0-GA-2014-620327 and by the Ministry of Industry and Trade, Russian Federation. Further info on HEXAFLY-INT can be found on http://www.esa.int/hexafly-int.

\section{REFERENCES}

1. Steelant J. (2009). Achievements obtained on AeroThermal Loaded Materials for High-Speed Atmospheric Vehicles within ATLLAS. In Proc. $16^{\text {th }}$ AIAA/DLR/DGLR "International Space Planes and Hypersonic Systems and Technologies Conference", Bremen, Germany, AIAA2009-7225.

2. Steelant, J. (2011). Sustained Hypersonic Flight in Europe: first achievements within LAPCAT II. In Proc. $17^{\text {th }}$ AIAA "International Space Planes and Hypersonic Systems and technologies conference", San Francisco, California, AIAA 2011-2243.

3. Steelant, J. et al. (2015). Conceptual Design of the HighSpeed Propelled Experimental Flight Test Vehicle HEXAFLY. In Proc. 20 ${ }^{\text {th }}$ AIAA "International Space Planes and Hypersonic Systems and technologies conference", Glasgow, Scotland, AIAA 2015-3539.

4. Hexafly-INT Team (2014). Part B "High-Speed Experimental Fly Vehicles-INTernational”, CIRA-CF-141132

5. Jung, W., Ettl, J., Kallenbach, A., Turner, J. (2014). Mission Definition and System Requirements, Work Package 2.0 - Launch Vehicle, Presentation at HEXAFLYINT MDR \& SRR, Capua, Italy

6. Favaloro, N., Rispoli, A., Vecchione, L., Pezzella, G., Carandente, V., Scigliano, R., Cicala, M., Morani, G., Steelant, J. (2015). Design Analysis of the High-Speed Experimental Flight Test Vehicle HEXAFLY-International. In Proc. $20^{\text {th }}$ AIAA "International Space Planes and Hypersonic Systems and technologies conference", Glasgow, Scotland, AIAA 2015-3607

7. Pezzella, G., Marini, M., Reimann B., Steelant, J. (2015). Aerodynamic Design Analysis of the HEXAFLY-INT Hypersonic Glider. In Proc. 20 $0^{\text {th }}$ AIAA "International Space Planes and Hypersonic Systems and technologies conference", Glasgow, Scotland, AIAA 2015-3644

8. Pezzella, G., van Brummen, S., Steelant, J. (2015). Assessment of Hypersonic Aerodynamic Performance of the EFTV-ESM Configuration in the Framework of the Hexafly-INT Research Project. In Proc. $8^{\text {th }}$ European Symposium on Aerothermodynamics for Space Vehicles, Lisbon, Portugal

9. Pezzella, G., Carandente, V., Scigliano, R., Marini, M., Steelant J. (2015). Aerothermal Environment Methodology of the Hexafly-INT Experimental Flight Test Vehicle (EFTV). In Proc. $8^{\text {th }}$ European Symposium on Aerothermodynamics for Space Vehicles, Lisbon, Portugal 
10. Tauber, M.E. (1989). A review of high-speed, convective, heat-transfer computation methods. Technical Paper 2914, NASA.

11. Glass, D.E., Capriotti, D.P., Reimer, T., Kütemeyer, M., Smart, M. (2014). Testing of DLR C/C-SiC and C/C for HIFiRE 8 Scramjet Combustor. In Proc- $19^{\text {th }}$ AIAA "International Space Planes and Hypersonic Systems and Technologies Conference", Atlanta, Georgia

12. ANSYS Inc. (2009). Thermal analysis guide, Release 12.1.

13. ANSYS Inc. (2009). Structural analysis guide, Release 12.1. 